\title{
A General Model for BOP Decarburization
}

\author{
Kuo-Chih CHOU, Uday B. PAL ${ }^{1)}$ and Ramana G. REDDY ${ }^{2)}$
}

Visiting Professor, Department of Materials Science and Engineering, Massachusetts Institute of Technology. On leave from University of Science and Technology Beijing, Beijing, China. Massachusetts Institute of Technology, Cambridge, MA 02139, U.S.A. Engineering, University of Nevada, Reno, NV 89557, U.S.A.

1) Department of Materials Science and Engineering, 2) Department of Chemical and Metallurgical

(Received on March 16, 1993; accepted in final form on May 21, 1993)

\begin{abstract}
The decarburization in the BOP (Basic Oxygen Process) has been modeled. The model was formulated based on the industrial data relating the temperature and the carbon content of the bath. Several formulae for calculating the variation of carbon and oxygen contents in the liquid metal as well as carbon monoxide composition in the gas phase were derived as a function of blow time, oxygen blow rate, gas purity and melt weight; these derivations were done for low $(<0.3 \%)$ as well as high $(>0.3 \%) \mathrm{C}$ levels. The model was applied to a typical BOP operation and the calculated results show good agreement between predicted values and the actual operating values. It is expected that this model can be used as a reference for analyzing various steelmaking processes.
\end{abstract}

KEY WORDS: decarburization; kinetics; thermodynamics; BOP; modeling.

\section{Introduction}

Decarburization is the most important reaction governing productivity in BOP. It influences other important reactions such as desulphurization and dephosphorization which are in turn instrumental in determining the final quality of steel. A good understanding of the BOP decarburization process will also help us in increasing the scrap melting capacity. As a result, the BOF (Basic Oxygen Furnace) process has been widely studied in both laboratory and industrial scales, ${ }^{1-5)}$ and various different types of models have been proposed to describe the decarburization mechanism and predict the entire process.

It is necessary that all models including metallurgical process models be continuously improved based on the following two criterions: (1) Assumptions be minimum and realistic and (2) The model should not only offer a good prediction of the process but also reflect the real nature of the process so as to enhance the understanding of the process. Based on these two criterions, the BOP decarburization model has been further developed in this paper.

Recently Vensel et al. ${ }^{6)}$ have proposed a decarburization model for BOP. This model has successfully predicted the change in gas composition as a function of blow time and the prediction matches well with the industrial practice. However, there are certain aspects of this model that can be further improved in order to extend its applicability. The model is based on the three following assumptions: (1). $[\% \mathrm{C}]=4-0.27 t$ when $[\% \mathrm{C}]<0.3,(2) . \quad[\% \mathrm{C}]=\exp [-(1.204+0.9 t)]$ when $[\% \mathrm{C}]>0.3$ and $(3) . T=1350+12.5 t$. In these three assumptions, $[\% \mathrm{C}], T$ and $t$ are the percentage carbon in solution, bath temperature and the blow time respectively and the starting $[\% \mathrm{C}]$ in the bath is assumed to be $4 \%$. All three assumptions are empirically determined from a given set of industrial data without giving any explanations of their physical significance. According to the first assumption, the decarburization rate does not change during the blow and is not a function of the oxygen blow rate. This would completely restrict the application of the model in the narrow range where the decarburization rate is fixed and controlled by carbon transfer in melt. In reality, the BOP decarburization process is a complicated kinetic phenomena which actually involves two different types of rate controlling steps. In the high carbon concentration range the rate controlling step is likely to be oxygen transfer, and in the low concentration range the rate controlling step is carbon transfer in the bath. Vensel, Henien and Dauby's model did not take into consideration the above mentioned kinetic phenomena. Instead, they avoided this problem by making the first two assumptions. While applying the model to an actual process Vensel et al. also assumed that the activity coefficient of carbon was only a function of the carbon content and not the temperature. This is once again not realistic because the temperature changes during the course of the blow.

In this paper we have formulated the model based on one simple assumption relating the variation of the carbon content with temperature. Our model is derived by combining both thermodynamic and kinetic factors. It addresses the above mentioned short comings of the previous model and thus gives a more realistic physical 
picture of the actual BOP decarburization process.

\section{Variation of Bath Temperature and Carbon Content during Scrap Melting and Oxygen Blow}

Scrap is extensively used in the steelmaking process due to production and economic incentives. In the presence of scrap, the temperature of the converter bath during the decarburization process will vary above the liquidus of the $\mathrm{Fe}-\mathrm{C}$ phase diagram as shown in Fig. 1. This temperature variation can be explained in accordance with the mechanism of scrap melting. ${ }^{1-5)}$

Asai and Muchi $^{1)}$ have plotted the empirical data obtained by other investigators ${ }^{7-14)}$ on bath temperature and carbon concentration of molten steel in the converter on the iron carbon phase diagram (Fig. 1). They found that, the data points corresponding to the process wherein no scrap was added showed a linear relationship between the temperature and the carbon concentration during oxygen blow. However, when scrap is added the distribution of these data points fell on the temperature axis and became close and parallel to the liquidus line. Asai and Muchi $^{11}$ have given a theoretical explanation for their finding and proposed a mathematical model in good agreement with the experimental observation.

Burdakov and Varsharvskii ${ }^{2)}$ have gathered industrial data relating the bath temperature and the carbon content for several BOF processes, which were also scattered in the area above the liquidus of the $\mathrm{Fe}-\mathrm{C}$ phase diagram and had a near linear relationship.

The observations made by the previous investigators concerning the relation between the bath temperature and the carbon content will be taken as input variables for our model to depict the decarburization behavior in detail in the BOF process. For the sake of convenience, a carbon steel smelting in the BOP will be taken as an example to illustrate the whole process. Assume hot metal at $1400^{\circ} \mathrm{C}$ with a high carbon content is initially charged (for instance, liquid iron containing $4 \%$ carbon) into the converter with some scrap and after blowing, the bath temperature varies linearly with carbon content as follows

$$
T=1873-50 \cdot[\% \mathrm{C}]
$$

where $T$ represents the absolute temperature of the bath and $[\% \mathrm{C}]$ is the carbon concentration in the bath expressed in weight percent. This relationship between the bath temperature and the carbon content will be used in this paper to develop equations for calculating carbon and oxygen contents in the liquid metal as well as $\mathrm{CO}$ composition in the gas phase as a function of oxygen blow and decarburization time. It may be noted that, Eq. (1) represents line AB in Fig. 1 which is actually close to Imai et al.'s data. ${ }^{10)}$ One may choose any kind of temperature $v s$. carbon content curve $(T-C$ curve) to use our model; it is not necessary that the $T-C$ curve be a straight line. This is a general model which can fit different kind of processes.

\section{Relationship between Gas Composition and Liquid Carbon Content in BOP}

When oxygen blows into the liquid metal, the carbon in hot metal will be oxidized by oxygen to form carbon dioxide. At an elevated temperature, the $\mathrm{CO}_{2}$ will react again with bath carbon according to the Boudouvard reaction

$$
\mathrm{CO}_{2}+\mathrm{C}=2 \mathrm{CO}
$$

where the " $\underline{C}$ " represents the carbon dissolved in the hot metal. In accordance with the mass action law, we have

$$
K_{2}=\frac{p_{\mathrm{CO}}^{2}}{p_{\mathrm{CO}_{2}} \cdot a_{\mathrm{C}}}
$$

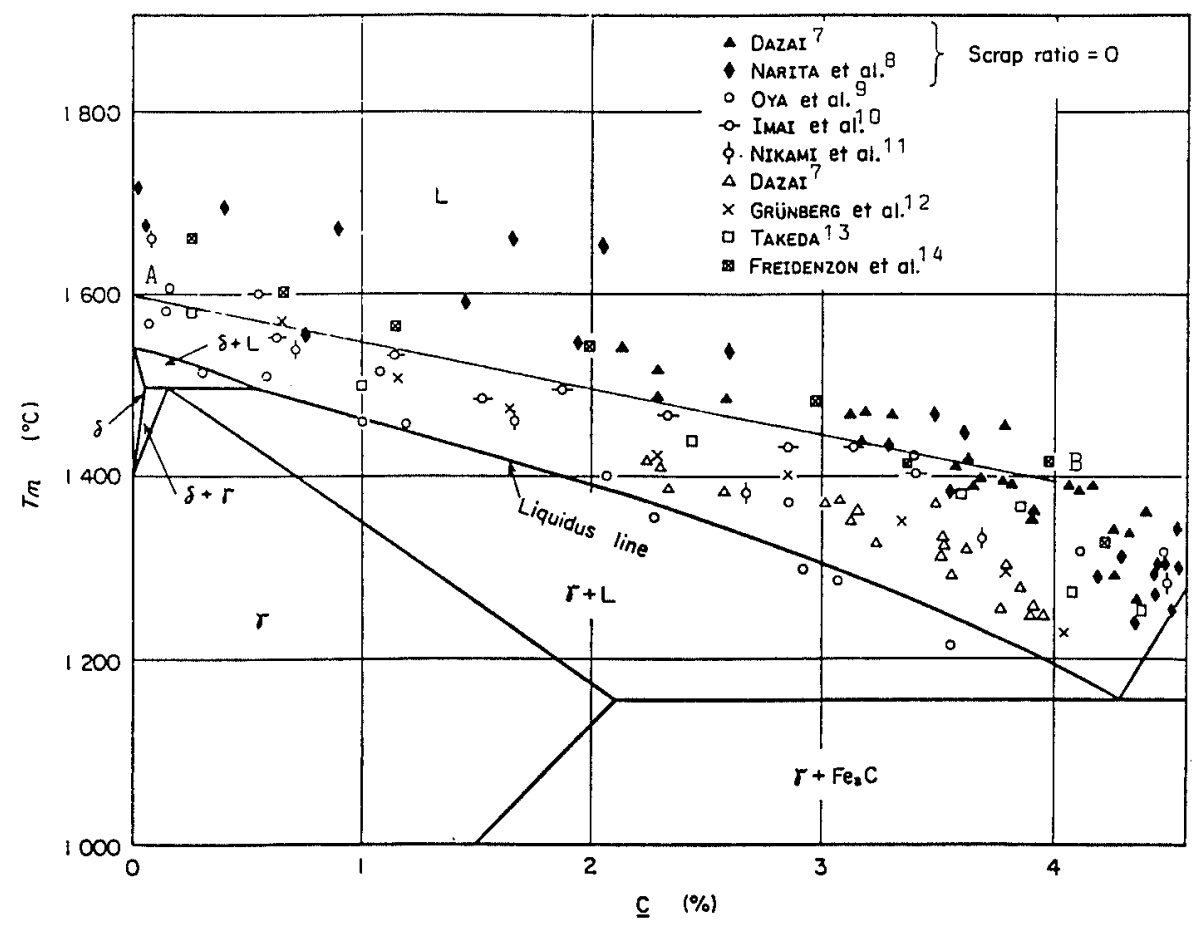

Fig. 1.

The $\mathrm{Fe}-\mathrm{C}$ binary phase diagram and the variation of bath temperature in BOP. (This plot is based on the Asai and Muchi ${ }^{1}{ }^{1}$ work. The reference numbers inside the plot have been changed in accordance with the reference numbers cited in this paper.) 
where $p_{\mathrm{CO}}, p_{\mathrm{CO}_{2}}$ represent the partial pressures of $\mathrm{CO}$, $\mathrm{CO}_{2}$ respectively, $a_{\mathrm{C}}$ indicates the activity of carbon in hot metal and $K_{2}$ is the equilibrium constant that is a function of temperature and can be derived in terms of standard Gibbs free energy data ${ }^{15)}$

$$
K_{2}=\exp \left[15.30-\frac{16759}{T}\right]
$$

Substituting Eq. (1) into Eq. (4) and combining with Eq. (3) yield

$$
\exp \left[15.30-\frac{16759}{1873-50 \cdot[\% \mathrm{C}]}\right]=\frac{p_{\mathrm{CO}}^{2}}{p_{\mathrm{CO}_{2}} \cdot a_{\mathrm{C}}}
$$

If the oxygen blowing into the converter bath is not pure but contains some inert gases such as nitrogen, argon ...etc. and the total pressure is assumed to be $P$, we would have

$$
\begin{aligned}
& p_{\mathrm{CO}}=P \cdot x_{\mathrm{CO}} \\
& p_{\mathrm{CO}_{2}}=P x_{\mathrm{CO}_{2}} \\
& p_{\mathrm{Inr}}=P x_{\mathrm{Inr}}
\end{aligned}
$$

where $x_{\mathrm{CO}}, x_{\mathrm{CO}_{2}}, x_{\mathrm{Inr}}$ represent the mole fractions of $\mathrm{CO}, \mathrm{CO}_{2}$ and inert gas in the decarburization zone respectively and

$$
x_{\mathrm{CO}}+x_{\mathrm{CO}_{2}}+x_{\mathrm{Inr}}=1
$$

On the other hand, the activity of carbon can be expressed in terms of the products of $[\% \mathrm{C}]$ and activity coefficient $f_{\mathrm{C}}$, i.e.

$$
a_{\mathrm{C}}=[\% \mathrm{C}] \cdot f_{\mathrm{C}}
$$

Substituting Eqs. (6) to (10) into Eq. (5) generates

$\exp \left[15.30-\frac{16759}{1873-50[\% \mathrm{C}]}\right]=\frac{P x_{\mathrm{CO}}^{2}}{\left(1-x_{\mathrm{Inr}}-x_{\mathrm{CO}}\right)[\% \mathrm{C}] f_{\mathrm{C}}}$

At present let us introduce two other quantities, $\chi_{\mathrm{CO}}$ and $\chi_{\mathrm{CO}_{2}}$ (relative contents of $\mathrm{CO}$ and $\mathrm{CO}_{2}$ in $\mathrm{CO}+\mathrm{CO}_{2}$ ). They are defined as (please note the difference between capital " $\chi$ " and lower case " $x$ ")

$$
\begin{aligned}
& \chi_{\mathrm{CO}}=\frac{x_{\mathrm{CO}}}{x_{\mathrm{CO}}+x_{\mathrm{CO}_{2}}}=\frac{x_{\mathrm{CO}}}{1-x_{\mathrm{Inr}}} \\
& \chi_{\mathrm{CO}_{2}}=\frac{x_{\mathrm{CO}_{2}}}{x_{\mathrm{CO}}+x_{\mathrm{CO}_{2}}}=\frac{x_{\mathrm{CO}_{2}}}{1-x_{\mathrm{Inr}}}
\end{aligned}
$$

Inserting Eqs. (12) and (13) into Eq. (11), we obtain

$$
\exp \left[15.30-\frac{16759}{1873-50[\% \mathrm{C}]}\right]=\frac{p \chi_{\mathrm{CO}}^{2} \cdot\left(1-x_{\mathrm{Inr}}\right)}{\left(1-\chi_{\mathrm{CO}}\right)[\% \mathrm{C}] f_{\mathrm{C}}}
$$

The above relation gives the dependence of relative content of the carbon monoxide on the carbon con-

\begin{tabular}{|c|c|c|c|c|c|c|c|c|c|c|}
\hline$[\% \mathrm{C}]$ & 4 & 3.5 & 3.0 & 2.5 & 2.0 & 1.5 & 1.0 & 0.8 & 0.6 & 0.3 \\
\hline$T(\mathrm{~K})$ & 1673 & 1698 & 1723 & 1748 & 1773 & 1798 & 1823 & 1833 & 1843 & 1853 \\
\hline$x_{\mathrm{CO}}$ & 0.9997 & 0.9997 & 0.9996 & 0.9995 & 0.9994 & $0.999 \mathrm{I}$ & 0.9986 & 0.9982 & 0.9975 & 0.9947 \\
\hline$-d[\% \mathrm{C}] / d t$ & 0.2570 & 0.2570 & 0.2570 & 0.2570 & 0.2570 & 0.2569 & 0.2568 & 0.2566 & 0.2565 & 0.2557 \\
\hline$t(\mathrm{~min})$ & 5.0000 & 6.9453 & 8.8906 & 10.836 & 12.782 & 14.728 & 16.675 & 17.454 & 18.234 & 19.405 \\
\hline$[\% \mathrm{O}] \cdot 10^{4}$ & 3.000 & 3.500 & 4.300 & 5.400 & 7.200 & 10.20 & 16.50 & 21.40 & 29.60 & 63.00 \\
\hline
\end{tabular}
centration in the hot metal during the BOP. Based on this relation the relative mole fraction of $\mathrm{CO}$ can be calculated if carbon content and $f_{\mathrm{C}}$ are known. Bensel et al. ${ }^{6)}$ have used the following expression for $f_{\mathrm{C}}{ }^{6,16)}$

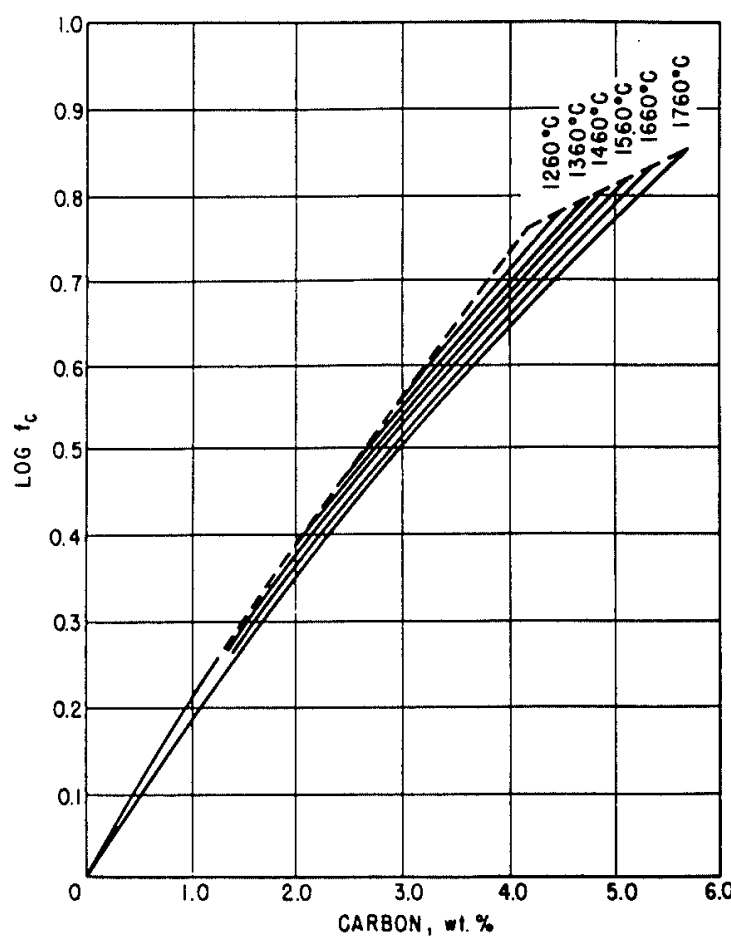

Fig. 2. Activity coefficient of carbon in liquid iron for the standard state $f_{\mathrm{C}} \rightarrow 1$ when $\left.[\% \mathrm{C}] \rightarrow 0 .{ }^{9}\right)$

Table 1. The time dependence of carbon and oxygen in liquid metal, carbon monoxide in gas phase as well as bath temperature in the BOP. (Given: Metal weight $=250 \mathrm{t}$; Blow rate $=600 \mathrm{Nm}^{3} / \mathrm{min} ; x_{\mathrm{Inr}}=0$ )

\begin{tabular}{ccccccccccc}
\hline$[\% \mathrm{C}]$ & 0.20 & 0.18 & 0.16 & 0.14 & 0.12 & 0.10 & 0.07 & 0.05 & 0.01 & 1871 \\
$T(\mathrm{~K})$ & 1863 & 1864 & 1865 & 1866 & 1867 & 1868 & 1870 & 1873 \\
$x_{\mathrm{Co}}$ & 0.9918 & 0.9909 & 0.9897 & 0.9883 & 0.9863 & 0.9836 & 0.9767 & 0.9678 & 0.8688 \\
$-d[\% \mathrm{C}] / d t$ & 0.1705 & 0.1534 & 0.1364 & 0.1194 & 0.1023 & 0.0853 & 0.0597 & 0.0426 & 0.0085 \\
$t(\mathrm{~min})$ & 19.750 & 19.840 & 19.941 & 20.054 & 20.186 & 20.314 & 20.645 & 20.932 & 22.304 \\
{$[\% \mathrm{O}] \cdot 10^{4}$} & 96.70 & 108 & 122.10 & 140.2 & 164.5 & 198.6 & 286.9 & 405.7 & 2226.5 \\
\hline
\end{tabular}




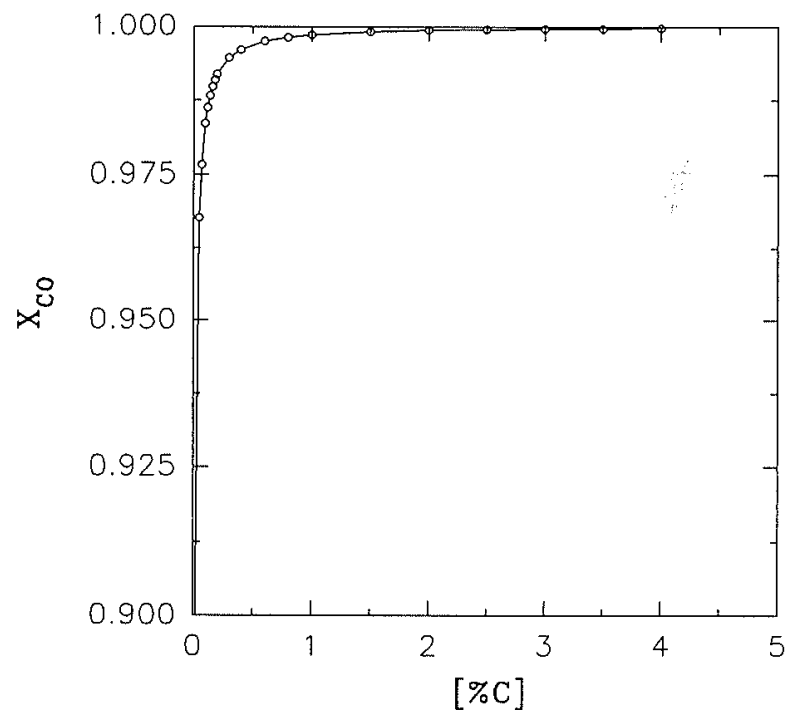

Fig. 3. The dependence of carbon monoxide in gas phase on carbon content in liquid metal in BOP assuming $x_{\mathrm{Inr}}=0$.

$$
f_{\mathrm{C}}=\alpha[\% \mathrm{C}]
$$

where, $\quad \alpha=0.167$ when $[\% \mathrm{C}]>1 \%$

$$
\alpha=0.200 \quad \text { when }[\% \mathrm{C}]<1 \%
$$

These are approximation formulae and they completely neglect the effect of temperature on $f_{\mathrm{c}}$. Rist and Chipman ${ }^{17)}$ have given a plot of $f_{\mathrm{C}} v s$. carbon content in liquid iron with a cluster of radial curves as shown in Fig. 2, which involves both composition and temperature factors and can be characterized by the following polynomial equation obtained from least square

$$
\begin{aligned}
\log f_{\mathrm{C}}= & 0.1666[\% \mathrm{C}]-0.01585[\% \mathrm{C}]^{2} \\
& +9.9613 \cdot 10^{-7}[\% \mathrm{C}]^{3}(T-273) \\
& +3.0246 \cdot 10^{-5}[\% \mathrm{C}](T-273)
\end{aligned}
$$

The correlation coefficient of the above least square fit is 1, which means that Eq. (18) is a good approximation of the data. Based on these data, the $\chi_{\mathrm{CO}}-[\% \mathrm{C}]$ curve can be calculated by simultaneously solving Eqs. (1), (14) and (18). The relevant calculated results are listed in Table 1 and plotted in Fig. 3, which will be used in the following sections for further derivations.

\section{Time Dependence of Bulk Carbon, $\mathrm{CO}$ Content in the Gas Phase and Bath Temperature in BOP}

The decarburization rate depends on the oxygen blow rate into the furnace. If the rate of oxygen blow is $d n_{\mathrm{O}_{2}} / d t(\mathrm{~mol} / \mathrm{min})$ and the decarburization rate $d n_{\mathrm{C}} / d t$, then from mass balance consideration, we should have the following relation

$$
\left(1-x_{\mathrm{Inr}}\right) \frac{d n_{\mathrm{O}_{2}}}{d t}=-\frac{d n_{\mathrm{C}}}{d t}\left(\chi_{\mathrm{CO}_{2}}+\frac{1}{2} \chi_{\mathrm{CO}}\right)
$$

where the factor $\left(1-x_{\text {Inr }}\right)$ reflects the purity of oxygen as mentioned above and $x_{\text {Inr }}$ represents the mole fraction of inert gas in the gas phase. The negative sign stems from the decreasing carbon content during decarburization.
In an industrial practice, one prefers to use weight percent, $[\% \mathrm{C}]$, instead of moles for expressing carbon concentration in hot metal, and the flow rate $Q_{0}$ $\left(\mathrm{Nm}^{3} / \mathrm{min}\right.$ ) instead of $d n_{\mathrm{O}} / d t$ for oxygen consumed. Using these units Eq. (19) becomes (Appendix I)

$$
\frac{d[\% \mathrm{C}]}{d t}=\frac{-Q_{\mathrm{o}}\left(1-x_{\mathrm{Inr}}\right)}{1.87 \cdot 10^{-5}\left(1-0.5 \chi_{\mathrm{CO}}\right) w_{t}}
$$

where $w_{t}$ represents the bath weight in gram.

Since the function of $\chi_{\mathrm{co}}$ with respect to $[\% \mathrm{C}]$ has already been obtained (Eq. (14)) in the last section, substituting this relation into Eq. (20) we can calculate the rate of decarburization as a function of the process parameters. However, it may be noted that the results obtained using this equation agree well with the data reported in the literature when $\% \mathrm{C}$ in the bath is greater than 0.3 . When carbon content is less than 0.3 , the decarburization will be controlled by transport of $\mathrm{C}$ in the melt instead of oxygen and it can be expressed as

$$
\frac{d n_{\mathrm{C}}}{d t}=-k_{\mathrm{d}} A\left(C_{b}-C_{i}\right)
$$

where $C_{b}$ and $C_{i}$ indicate the bulk and interfacial concentration of $\mathrm{C}$ in the metal bath and at the bath/oxygen interface respectively (in $\mathrm{mol} / \mathrm{cc}$ ), $k_{\mathrm{d}}$ is the mass transfer coefficient (in $\mathrm{cm} / \mathrm{sec}$ ) and $A$ is the bath/oxygen interface area $\left(\mathrm{cm}^{2}\right)$.

Since the reaction between carbon and oxygen at high temperatures is very fast, $C_{i}$ is negligible and hence Eq. (21) can be written as

$$
\frac{d n_{\mathrm{C}}}{d t}=-k_{d} A C_{b}
$$

or

$$
\frac{d[\% \mathrm{C}]}{d t}=-\frac{k_{d}}{V} A[\% \mathrm{C}]
$$

where $V$ is the melt volume. Thus, we can use Eq. (20) to describe the decarburization when $\% \mathrm{C}>0.3$, and when $\% \mathrm{C}<0.3$ we can use $\mathrm{Eq}$. (23)

For instance, when the metal weight, $w_{t}$, is $250 \mathrm{t}$, the oxygen flow is $Q_{0}=600 \mathrm{Nm}^{3} / \mathrm{min}$ and the gas used is pure $\left(x_{\mathrm{Inr}}=0\right)$, the decarburization rate, the decrease of $\mathrm{C}$ content in the bath as a function of blow time are calculated using Eq. (20) (when \%C>0.3) and Eq. (23) (when $\% \mathrm{C}<0.3$ ). The relative composition of carbon monoxide $\chi_{\text {co }}$ as a function of blow time can also be determined by combining Eqs. (14), (20) and (23). The results are listed in Table 1 and plotted in Figs. 4, 5 and 6 . These calculations were performed by integrating Eq. (20) from $t=5$ since the carbon does not oxidize until all the silicon has been removed and this was assumed to take $5 \mathrm{~min}$ after start of blowing. ${ }^{5,6)}$ Using Eq. (20) the time taken to lower the $\% \mathrm{C}$ from 4 to 0.3 was found to be $19.405 \mathrm{~min}\left(t_{\mathrm{C}}\right)$. Integrating Eq. (23) from $0.3 \% \mathrm{C}$ to $[\% \mathrm{C}]$ and the corresponding blowing time from $t_{\mathrm{C}}(=19.405)$ to $t$ yields

$$
[\% \mathrm{C}]=0.3 \exp \left(-k_{d} \frac{A}{V}\left(t-t_{\mathrm{C}}\right)\right)
$$




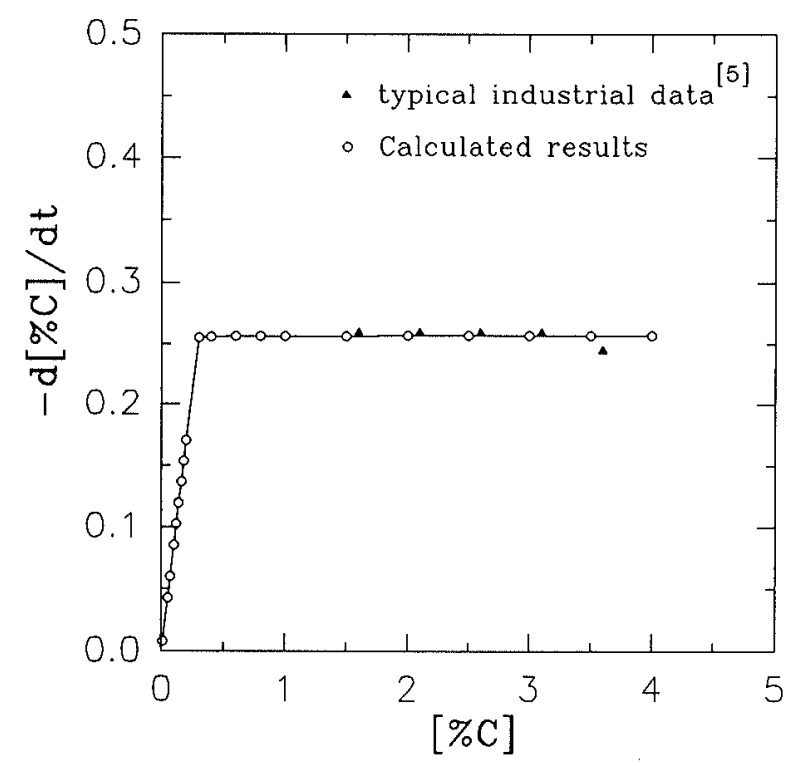

Fig. 4. The decarburization rate with respect to the carbon content in liquid iron in BOP.

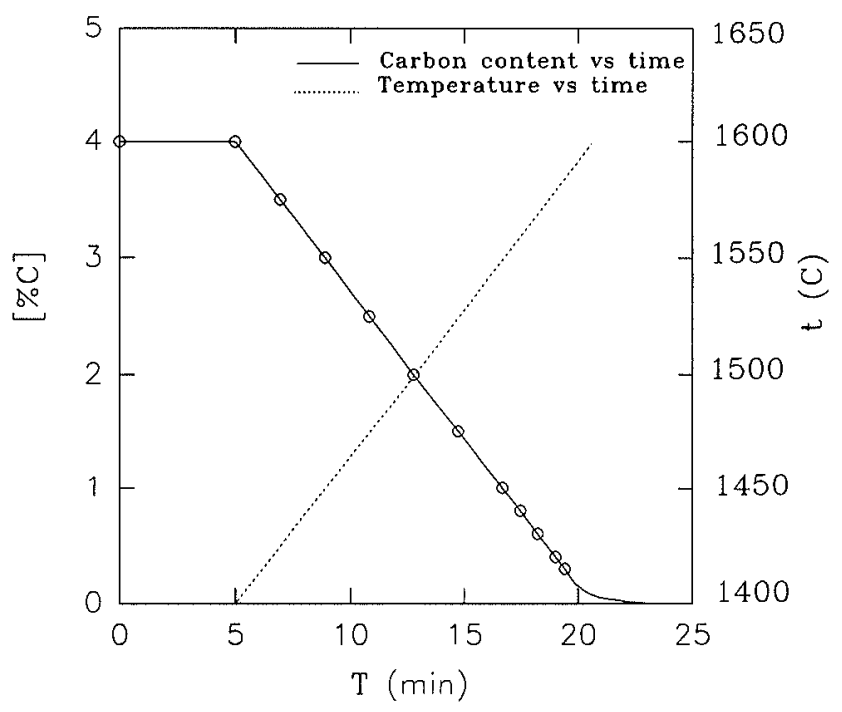

Fig. 5. The time dependence of bulk carbon and bath temperature in BOP.

The constant $\left(k_{d} A / V\right)$ can be determined in terms of the decarburization rate at $[\% \mathrm{C}]=0.3$ using $\mathrm{Eq}$. (20) and substituting in Eq. (23); $\left(k_{\mathrm{d}} A / V\right)$ was found to be 0.8525 . Hence Eq. (24) can be written as

$$
[\% \mathrm{C}]=0.3 \exp (-0.8525(t-19.405))
$$

According to the above mentioned model, the results presented in Table 1, Figs. 4, 5 and 6 are in good agreement with the industrial data reported in the literature. ${ }^{5,6)}$ From these figures it is evident that the decarburization rate between 4 to $0.3 \% \mathrm{C}$ is practically constant $(-0.2569 \% \mathrm{C} / \mathrm{min})$ but below $0.3 \% \mathrm{C}$ it drops quite drastically (Fig. 4). Similarly the $\mathrm{CO}$ content in the gas phase is very high initially during the oxygen blow but at near turndown there is a significant drop in CO content of the gas phase.

Finally, by incorporating the variation of $\% \mathrm{C}$ with temperature in Eq. (1), we can calculate the variation of bath temperature as a function of the oxygen blow time.

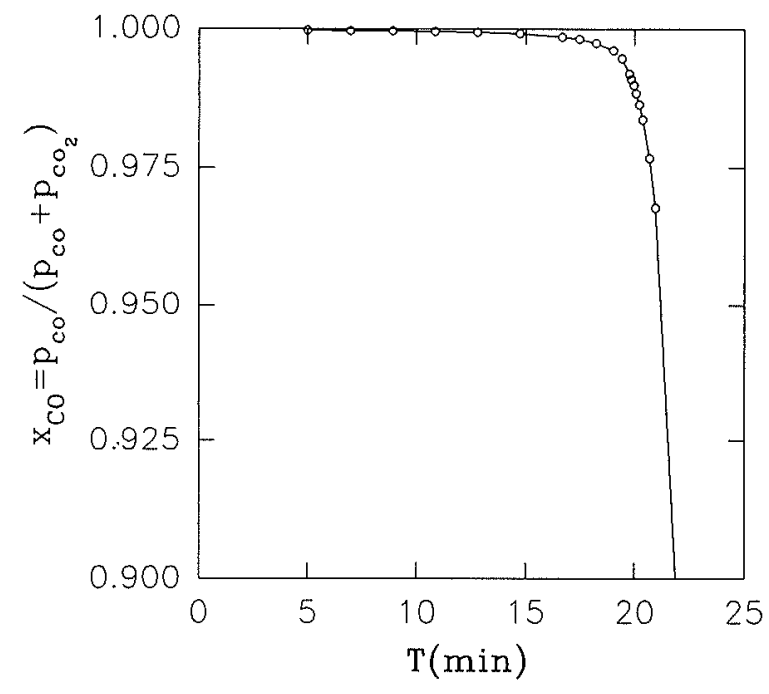

Fig. 6. The variation of gas composition with blowing time.

This is shown in Fig. 5 and is also in good agreement with the industrial data reported in the literature. ${ }^{5,6)}$

\section{Variation of Oxygen in Metal Bath}

The oxygen concentration in the metal bath can be calculated in terms of the following reaction

$$
\underline{\mathrm{C}}+\underline{\mathrm{O}}=\mathrm{CO}
$$

where $\underline{O}$ represents the oxygen dissolving in the hot metal. The mass action law corresponding to the above reaction is

$$
K_{27}=\frac{p_{\mathrm{CO}}}{a_{\mathrm{C}} \cdot a_{\mathrm{o}}}
$$

where $K_{27}$ is the equilibrium constant and $a_{\mathrm{O}}$ activity of oxygen in liquid metal. If the activity coefficients, $f_{\mathrm{C}}, f_{\mathrm{O}}$, are used instead of activities, then we have

$$
K_{27}=\frac{p_{\mathrm{Co}}}{[\% \mathrm{C}][\% \mathrm{O}] f_{\mathrm{C}} f_{\mathrm{O}}}
$$

or

$$
\ln [\% \mathrm{C}][\% \mathrm{O}]=\ln P+\ln x_{\mathrm{Co}}-\ln K_{27}-\ln f_{\mathrm{C}}-\ln f_{\mathrm{o}}
$$

where $\ln P=0$ ( $P=1 \mathrm{~atm})$ and $\ln K_{27}$ is a function of temperature and can be written as ${ }^{15)}$

$$
\ln K_{27}=4.77+\frac{2692.5}{T}
$$

$f_{\mathrm{C}}$ can be expressed by (Eq. (18)), while $f_{\mathrm{O}}$ can be estimated in terms of Wagner's interactive coefficients. In this case only carbon and oxygen in the liquid metal were considered. Based on the Elliott et al. data, ${ }^{18,19)} f_{\mathrm{O}}$ can be expressed as

$$
\ln f_{\mathrm{o}}=0.4606[\% \mathrm{O}]+0.2994[\% \mathrm{C}]
$$

Substituting Eqs. (18), (30) and (31) into Eq. (29) yields

$$
\ln [\% \mathrm{O}][\% \mathrm{C}]=\ln x_{\mathrm{co}}-\left(4.77+\frac{2692.5}{T}\right)
$$




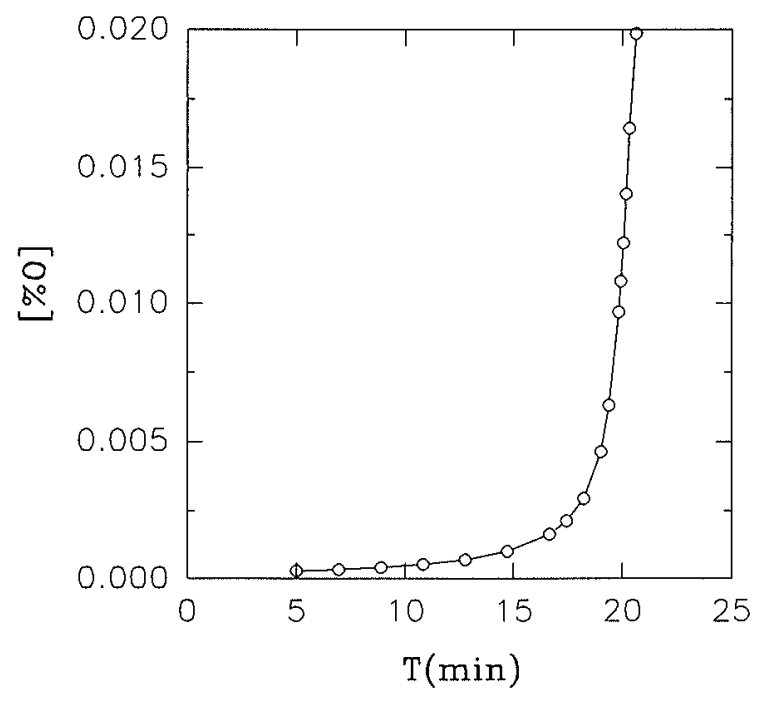

Fig. 7. The relation between bath oxygen and blowing time in BOP.

$$
\begin{aligned}
& -2.303\left(0.1666[\% \mathrm{C}]-0.01585[\% \mathrm{C}]^{2}\right. \\
& +9.9613 \cdot 10^{-7}[\% \mathrm{C}]^{3}(T-273) \\
& \left.+3.0246 \cdot 10^{-5}[\% \mathrm{C}] \cdot(T-273)\right) \\
& +(0.4606[\% \mathrm{O}]+0.2994[\% \mathrm{C}]) \ldots .(32)
\end{aligned}
$$

Since the $[\% \mathrm{C}]-t$ relation has already been found (Fig. 5), substituting this relation along with Eqs. (1) and (14) into Eq. (32), the curve of [\%O] vs. time can be evaluated and is plotted in Fig. 7. The results are also listed in the Table 1.

\section{Discussion}

A series of formulae for calculating temperature, carbon and oxygen compositions in the hot metal, carbon monoxide content in the gas phase and melt temperature as a function of decarburization time, oxygen blow rate and melt weight have been derived. The derivations were based on an assumed typical variation that exists between the temperature and the carbon content of the bath during decarburization. The calculated results were found to agree well with the industrial data. This indicated that the model and the methodology can be applied to other steelmaking processes for which the relationship between the temperature and the carbon content is known.

The inert gas in the blow can influence the decarburization process in two opposing ways. From Eq. (20) it is evident that by increasing the inert gas content in the blow, the decarburization rate will decrease. However from Eq. (14), it is seen that an increase in the inert gas content will increase the relative composition of the $\mathrm{CO}\left(\chi_{\mathrm{co}}\right)$ which in turn will result in increasing the decarburization rate. Therefore, from the foregoing it appears that the total effect on decarburization will depend upon which factor is dominant. It is well known that, at an elevated temperature $\left(>1000^{\circ} \mathrm{C}\right)$, the relative composition $\mathrm{CO}$ will be around $99 \%$. Therefore, by increasing the inert gas content in the blow, we will not be able to significantly increase the relative composition of $\mathrm{CO}$. Hence, as mentioned above, an increase in the inert gas content in the blow will decrease the decarburization rate. This is probably the reason as to why pure oxygen is chosen for blowing in order to increase the productivity of the vessel.

According to Eq. (20), an increase in the oxygen flow rate $\left(Q_{0}\right)$ will increase the decarburization rate. However, there are some practical limitations on the oxygen blow rate that can be used. The oxygen blow rate will depend upon many factors such as the equipment capacity, oxygen supply, plant capacity, lance type, refractories and other safety factors. A complete discussion involving all these factors is beyond the scope of this paper.

\section{Conclusions}

(1) A model has been developed for the decarburization process in BOP assuming that the relationship between the bath temperature and the carbon content is known.

(2) This model enables us to calculate the carbon and oxygen contents in the liquid metal, the carbon monoxide composition in the gas phase and the temperature of the liquid metal as a function of decarburization time for a given blow rate, gas purity and melt weight.

\section{REFERENCES}

1) S. Asai and T. Muchi: Tetsu-to-Hagané, 56 (1970), 546; S. Asai and T. Muchi: Trans. Iron Steel Inst. Jpn., 11 (1971), 107.

2) D. D. Burdakov and A. P. Varshavskii: Stal in English, 8 (1967), 647.

3) R. D. Pehlke, P. D. Goodell and R. W. Dunlap: Trans. AIME, 233 (1965), 1420.

4) R. G. Olsson, et al:: Trans AIME, 233 (1965), 1654.

5) G. H. Geiger, P. Kozakevitch, M. Olette and P. V. Riboud: BOF Steelmaking, ed. by R. D. Pehlke, W. F. Porter, R. F. Urban and J. M. Gaines, Proc. Tech. Division ISS/AIME, (1982), 302.

6) D. A. Vensel, H. Henein and P. H. Dauby: Iron and Steelmaking Trans. ISS/AIME, (1987), Feb., 45.

7) S. Dazai: Paper presented at the 19th Committee of Japan Society for the Promotion of Science, (1967, Oct.).

8) K. Narita, A. Tomita, S. Koyama, T. Ito and Y. Hirooka: Tetsu-to-Hagané, 55 (1969), 59.

9) T. Oya, I. Furugaki and A. Minami: Tetsu-to-Hagané, 51 (1965), 748 .

10) R. Imai, K. Kawakami, S. Miyoshi and S. Jinbo: Nippon Kokan Tech. Rep., 39 (1970), 19.

11) K. Nikami, K. Matsuda, T. Koyano and T. Yasui: Tetsu-toHagané, 52 (1966), 1491.

12) K. Grunberg, W. Schleicher and R. Kung: Stahl Eisen, 80 (1960), 277

13) K. Takeda: Tetsu-to-Hagané, 48 (1962), 1085.

14) E. Z. Freidenzon, V. G. Udovenko, Yu. V. Torshilov, G. M. Kompaniets, M. A. Tretyakov, V. M. Baranov, D. F. Nagovitsin, S. A. Donski and A. I. Pastukhov: Stal in English, (1965), June, 469

15) J. F. Elliott, M. Gleiser and V. Ranakrishna: Thermochemistry for Steelmaking, Vol. II, Addison-Wesley Pub. Co., Inc., New York, (1963), 619.

16) E. T. Turkdogan: BOF Steelmaking, ed. by R. D. Pehlke, W. F. Porter, R. F. Urban and J. M. Gaines, Proc. Tech. Division ISS/AIME, (1982), 153.

17) A. Rist and J. Chipman: Rev. Met., 53 (1956), 796

18) J. F. Elliott, M. Gleiser and V. Ramakrishna: Thermochemistry for Steelmaking, Vol. II, Addison-Wesley Pub. Co., Inc., New York, (1963), 566. 
19) C. H. P. Lupis and J. F. Elliott: Trans. Met., Soc. AIME, 233 (1965), 257.

\section{Appendix. The Deduction of Eq. (20) from Eq. (19)}

According to Eq. (19), we have

$$
\frac{d n_{\mathrm{C}}}{d t}=-\frac{\left(1-x_{\mathrm{Inr}}\right) d n_{\mathrm{O}_{2}}}{\left(1-0.5 \chi_{\mathrm{Co}}\right)}
$$

Since

$$
\frac{d n_{\mathrm{C}}}{d t}=\frac{w_{t}}{12 \cdot 100} \frac{d[\% \mathrm{C}]}{d t}
$$

where $w_{t}$ represents the bath weight in gram and $[\% \mathrm{C}]$ indicates the weight percent of carbon. On the other hand, $d n_{\mathrm{O}_{2}} / d t$ can be expressed as

$$
\frac{d n_{\mathrm{O}_{2}}}{d t}=\frac{P}{R T} \frac{d V}{d t}
$$

where $P, T, R$ indicate pressure (atm), absolute temperature (degree) and gas constant and $V$ represents the volume of oxygen. If the standard volume " $V_{N}$ " is used instead of the volume at designated $P, T$, then

$$
V=\frac{V_{N}}{273} \frac{T}{P}
$$

Substituting Eq. (A-4) into Eq. (A-3) yields

$$
\frac{d n_{\mathrm{O}_{2}}}{d t}=\frac{1}{273 R} \frac{d V_{N}}{d t}=\frac{10^{3}}{273 \cdot R} Q_{0} \quad\left(\mathrm{Nm}^{3} / \mathrm{min}\right)
$$

where $Q_{0}$ denotes the oxygen rate in $\mathrm{Nm}^{3} / \mathrm{min}$. Combining Eqs. (A-1), (A-2), (A-5) and rearranging it yields Eq. (20) 